\title{
Betwixt and Between: Creative Writing and Scholarly Expectations
}

Sue Norton

Technological University Dublin, susan.norton@tudublin.ie

Follow this and additional works at: https://arrow.tudublin.ie/aaschlanart

Part of the Creative Writing Commons

\section{Recommended Citation}

Norton, S. (2013) Betwixt and Between: Creative Writing and Scholarly Expectations. New writing: International journal for the theory and practice of creative writing, Vol. 10:1, 2013. doi:10.1080/ 14790726.2012.694451

This Article is brought to you for free and open access by the Languages at ARROW@TU Dublin. It has been accepted for inclusion in Articles by an authorized administrator of ARROW@TU Dublin. For more information, please contact arrow.admin@tudublin.ie, aisling.coyne@tudublin.ie,gerard.connolly@tudublin.ie. 


\section{Betwixt and Between: Creative Writing and Scholarly Expectations}

(Pre-Print Author's Accepted Copy, New Writing: The International Journal for the Theory and Practice of Creative Writing), Vol. 10: 1, 2013.

I teach English in a College of Arts and Tourism in an Institute of Technology in Dublin. The institute is one of the largest providers of higher education in Ireland, and it distinguishes itself with small-class sizes, community outreach and engagement, and excellence in teaching. It is, as its name indicates, an institute of technology, but it has aspirations to become a University.

My institute has, no differently than many other organisations of higher learning, sought to boost its reputation for research. It favours research with a capital R, meaning research that conforms to the usual higher education rhetoric surrounding research (such as "world class standards,” “attracts external funding,” “internationally recognised”) and that privileges predictable scholarly outputs such as articles in peer reviewed journals, refereed conference proceedings, and chapters in books.

Some of the institute's long-tenured teaching staff, I have heard, do not have the word research featuring in their contracts and do not necessarily regard themselves as having a research remit. A great many are research active, though, and I count myself among them.

Not only have I the word research featuring quite prominently in my contract, but I have a genuine wish to produce it. Publishing is nearly all I think about at times. But I face a negative bias: while the institute purports to respect "Creative Practice" and 
"Professional Practice" as categories of Research and Scholarly Activity, it mostly respects refereed journals, academic conference papers, chapters in book, and of course, scholarly books. But what I find myself most driven to do, most consumed by, really, is to write creative non-fiction, usually straightforward, beginning-middle-and-end essays, containing as much wit and wisdom as I have mustered in my forty eight years. I publish these essays in various fora ranging from commentary style magazines and e-zines, to literary and quasi-literary journals, to anthologies and radio broadcasts. Seeking reputable publication involves constant effort and often wasted anticipation. What I spend much time doing is writing query and submission letters - many, many - and then waiting. While I wait, I try to write the next essay. I maintain this rolling process throughout the academic year and straight through the summer. With a full teaching load and a full administrative load, I am constantly at work.

Teaching and writing are what I love, so I am not complaining, just explaining.

I began my creative writing pursuits about a year after the post-traumatic stress of my $\mathrm{PhD}$ wore off. The writing of my dissertation, which was on representations of family in contemporary American fiction, was, for me, more draining than rewarding. I had undertaken a PhD mainly because I wanted a permanent job as an English lecturer, and I knew I wouldn’t be considered without one. How difficult could a PhD be? I had done two English degrees already. But I soon learned that while I take pleasure in writing, I take much less pleasure in writing literary criticism. I love to read literature, to be sure, and I love teaching it. But writing about it is, as the world of academic publishing would have it, best left to those who can theorise or contextualise from a refined critical distance. Me, I am built to reflect and articulate, not to research and 
'place within a particular aesthetic and / or ideological and / or phenomenological tradition.'

So in 1999, I took up my present full-time, permanent position as a Lecturer of English, and I took it up with glee. My wide remit has been to teach English language, literature, culture, and writing skills to mostly Irish-born students and also to non-native speakers of advanced-level English from other countries. Quickly I began cobbling together courses that reflected my tastes and interests and that I felt would serve my students well. These included Creative Writing, Rhetoric and Writing Skills, Discourse Analysis, Written Expression and Textual Analysis, Literature of the English Speaking World, and Applied Grammar and Writing Skills. I could not have been happier. I still am.

Most of my teaching timetable involves pure writing instruction. Yet as a composition writer myself, my own creative output is worth seemingly little in institutional terms. My published and broadcast essays garner me not nearly the professional credibility that, for instance, refereed conference proceedings would or peer reviewed literary criticism in a scholarly journal. What I find most baffling about this cycloptic merit system is that it diminishes those professional or creative activities that relate most directly to my teaching. Given that I spend a great deal of my classroom contact time (roughly sixteen hours per week) engaged in the instruction of writing, shouldn't my own published writing, though not necessarily scholarly or academically investigative, be understood as a mark of professional calibre?

One day I put this inconsistency to a research-ambitious colleague at a faculty symposium on the institute's "research strategy” (higher education nomenclature is quite 
revealing), and he exclaimed, “well, someone can’t just go mountain climbing and call that research!” "Why not,” I argued. If that someone is a Lecturer of Tourism in a College of Arts and Tourism such as our own, for instance, and the expedition is meant to further inform her scholarship, shouldn't it fundamentally “count”? He conceded the point. But I sensed my argument was only moderately convincing within the group as a whole.

My own theory about this demoralizing disparity between creative practice and so-called scholarly research is that many academic institutions have established tacit binary oppositions between "the scholarly and the creative," "the intellectual and the artistic,” oppositions that aren’t mutually exclusive at all. Literary criticism, for instance, is highly "creative." We would be hard pressed, I think, to find a literary critic who does not regard her scholarship, however objectively reasoned, as creative endeavour. Equally, a short essay I once published called "Wisdom through the Minutes,” which was about the ways in which canonical and non-canonical literature has sustained me through trying times, was thoroughly informed by the "academic” reading that I have carried out over the years in the pursuit of my degrees.

Really, there is nothing I can write, whether so-called scholarly or not, that does not bring to bear the academically-informed personality that is me. That my creative writing directly informs my teaching activities should, in my view, make it that much more academically worthy in the eyes of the institute.

Indeed the model of research that my institute has adopted, and somewhat adapted, is one outlined by the OECD, the Organisation for Economic and Co-Operative Development. It defines research and scholarship as "any creative work undertaken on a 
systematic basis in order to increase the stock of knowledge, including knowledge transfer, or to develop new materials useful for teaching and learning, or to add to the stock of creative works and includes applied, oriented and basic research, consultancy and experimental development.”

It is a superbly inclusive definition. But I sense its application is somewhat halfhearted.

We are routinely asked to upload all of our research "outputs" (more revealing nomenclature) onto the institute's research repository. Creative Practice, though included as a category in the institute's definition of research, isn't mentioned on the repository. Prominence is given to refereed articles and papers and to scholarly chapters. Non-peer reviewed articles can be submitted, and the repository does include several categories designated as "Other." Not surprisingly, the route to progression from Assistant Lecturer to Lecturer also privileges traditional scholarly outputs, such as articles in refereed journals, over other forms of disciplinary engagement. Once a month or so, the automated repository sends us by email the "usage statistics" of the material we have uploaded. These statistics reveal the number of other academics who have examined our work.

I have to wonder what our students would make of our priorities. Institutions of higher learning in Ireland are competing for so-called "customers.” My own institute has advertised itself as "one step closer to the real world," meaning, presumably, one step closer than the country's universities. What a laudable orientation, I feel. For shouldn't there be many institutions in higher education that do what mine has set out to do: that is, to guide graduates into the world of work? But if we are going to guide them there, we 
need to be well acquainted with it ourselves. And so, as academics, we ought to be respected for those aspects of our professional profiles that manifest our discipline-related engagement with the real world. A publishing writer who lectures in subject areas pertaining to writing, whether in a traditional English department or any other Arts or Humanities department, is likely to be well regarded by her students. But, ironically, she will win the regard of her institution much more readily by writing in fora meant not for the public, but for other academics. Academia has become worryingly solipsistic if the value system it regards most highly is its own.

Writing some years ago in the MLA’s publication Profession about society’s need for academics to engage more in "the broader world," the screen-writer / director and former Columbia English Professor John Romano expressed a scholarly sentiment that has stayed with me:

The indefinable sophistication about language and culture that an education in the humanities develops is exactly what's lacking in the public discourse. As you [academics] get smarter in your quarterly journals, more skeptical of current pieties, more deft in interpreting the culture through its signs, the public is getting dumber, intellectually clumsier, more naive about just the same sort of things. This is television's fault, surely, but it is also yours: the fault of those who might usefully be addressing the public and instead are locked in conversation with one another. (35)

While the intellectual shortcomings of the public may be a matter of opinion, academics are certainly locked in conversation with one another. One might say that, as intellectuals, we are "head-locked." We communicate with each other through refereeship and peer-review, and that is what we are rewarded for doing. We become 
preoccupied with benchmarking against others working in our disciplines, and in a certain sense we stray from our disciplines.

Such narrow focus distresses me. I came to English studies because I loved the written word. I want to both revel in it and ply it. I want to facilitate interested others to do the same. I do appreciate that institutions that employ people like me need to compete with other institutions, and they need to be engaged in all manner of institutional advancement. Most cannot "just" teach. Those working in both so-called "hard" and "soft" subjects in colleges, institutes, and universities have always and should always advance their frontiers. If I write a piece of rigorous scholarship, I am breaking new ground. But if I write an elegant essay for a general readership, I am tending the garden. Both promote growth.

To be fair, so-called "creative writing" is a difficult "output" to measure. Its quality will always be a matter of taste. And since its aim is not ordinarily to push any boundaries, except maybe aesthetic or experimental ones, it is pointless to attempt to referee it. One reader's drivel is another's poetry. Beauty is in the eye of the beholder. And so on. And, equally problematic for those intent on applying institutional metrics, compositions find their way into all sorts of publications, some prestigious and some not especially so. I happen to be very proud of an essay I once wrote about my hometown called “Ode to Hackensack (Seriously).” While I didn’t expect Atlantic Monthly to be interested in it, the good people of Bergen County, New Jersey, were, and it was published in a glossy periodical aimed at a large but local readership. It was a crafty piece of writing and I received some appreciative letters. One of my students who had come from Estonia to study in Dublin via (I couldn’t believe it) Hackensack, New Jersey, 
enjoyed reading it so much that she later wrote an ode to her own hometown in Estonia. I was immensely pleased.

But this kind of affirming, writerly-teacherly experience, whereby professional creative practice inspires student creative practice, just isn't the kind of “output” that a university metric system rewards.

I do not wish to dispute the value of peer review and external reading and traditional forms of scholarship, or of measuring scholarship. These practices are valuable, and anyway, they are here to stay. What I do wish to argue is that creative writing, and all other creative endeavor, is not scholarship in the usual sense but something cognate. Far from irrelevant to scholarship in the investigative sense of the term, creative writing is the artistic manifestation of disciplinary engagement. It is not a lesser form of scholarship. It is worthy of the high regard of universities and institutions whose faculty members are engaged in the teaching of practice-based courses and modules pertaining to writing. What better writing instructor than one who is also a publishing writer?

But "publishing writer" is, alas, another difficult-to-measure category. To be fair again to university metric systems, the Internet has made a kind of open-mic-night of the world of the printed, or, rather, the disseminated, word. Anyone who so chooses can be, in moments, internationally "published" just by setting up a blog. And anyone who is not thoroughly illiterate and who wants rather more external validation will very likely find someone else with a blog or a website to "publish" her work. I can think of several writers’ websites that accept, in my opinion, barely mediocre fiction and non-fiction. And I can think of many others that are as discerning as the most long-standing and prestigious literary journals. (Indeed a good number of the most long-standing and 
prestigious literary journals, such as Brevity, The Sun, and AGNI, host ample on-line content.)

But still, what is a self-respecting university metric system supposed to do with this modern day verbal proliferation. How can a university assess the "output" of its faculty?

Well, in the words of the best bumper sticker I have ever seen, it can "Subvert the Dominant Paradigm.” Universities should resoundingly favour the value to their students, to their communities, and therefore to their own strategic objectives of artistic and writerly endeavour. They should understand that creative practice may not be scholarship as conventionally understood, but it can be the lifeblood of the learnerteacher dyad, and it can be the thing that roots a university in the public's imagination. Many people know of my institute's Conservatory of Music and Drama's lunchtime concert series. Very few, I think, would be aware of its staff members' output of refereed articles in journals. Many people have heard the essays I have written for Irish radio. Very few have read the article on Anne Tyler's fiction that I once published in The Irish Journal of American Studies. So, University Hierarchies out there, subvert the dominant paradigm. And remember, too, that you really cannot judge a book by its cover. I know of one forthcoming scholarly edition whose "external" readers also happen to be, for the most part, the contributors themselves. How's that for getting around the metric system? Perhaps progressive universities of the future will feel less compelled to assess the output of faculty. For one thing, such assessment is demoralising and potentially counterproductive. For another, it is probably pointless. Most of us went into university life because we love our subject matters. We will inevitably manifest our enthusiasm in all of the ways that come naturally to us, whether through research, scholarship, 
pedagogy, creative practice, or mountain climbing. As long as we are engaged, everyone wins. We will bring honour to our institutions, and our institutions will benefit.

But if there must be a metric system, let it be one that is facilitative rather than judgmental. Refrain from shaming us into research or publication. Staff members at all levels need to be nurtured, not pressured, into publication. Here in my institute, I am only too pleased to say, the Learning and Teaching Centre seems to understand this. It publishes its own electronic journal called Level 3 featuring both refereed and nonrefereed papers and articles, and it also hosts workshops aimed at incorporating teaching practice into research. Another initiative is GradCAM, the Graduate School of Creative Arts and Media, that involves several other higher education organizations and seeks to combine "critical intellectual enquiry and creative practice" in the ways that it teaches and trains post-graduate students.

Schools and departments across higher education would be sensible to adopt a similar mentality in relation to staff. A helpful approach to fostering a culture of extracurricular engagement (critical, scholarly, creative...) might be for Heads of Departments to take appreciative account of the sorts of research, scholarly activity, and creative practice that their faculty members are inclined to carry out, and then seek to be broad and inclusive in measuring it. They might do so on the simple principle that scholarly activity is likely to increase in an academic culture that is inclusive and qualitative, rather than reductive and quantitative.

One excellent model of scholarly-creative inclusivity is the Journal called EnterText: An Interdisciplinary Humanities e-Journal published on-line by Brunel University, West London. It incorporates both critical and creative work and is highly scholarly in every traditional sense, but it is only partly refereed. In the words of its 
editors, "it aims to break down traditional classifications which limit the style and range of discussions. The old compartments and categories are here replaced with interdisciplinary, cross-cultural, trans-generic and experimental discourse. A distinctive feature is that the Journal gives equal weight to both rigorously refereed academic studies and textual or visual creative work.” It includes:

- refereed articles on topics in the arts, humanities and social sciences, such as are found in traditional academic journals. [And also] interviews with writers, artists, and other key cultural figures.

- creative writing, work in progress, and other kinds of creative text, verbal or visual, within the capabilities of the medium.

- a forum for readers' responses and discussion.

False dichotomies do not prevail at EnterText. Academic life would be so much more multi-faceted if all of higher education were so expansive. This journal's model takes account of the creative impulse, of scholarly rigour, and of the critical distance of the referee. And, perhaps most inspiring, it involves the active participation of the reader. By such a model, the perceived binary opposition that has become wedged between the scholarly and the creative is rightly acknowledged and simultaneously diminished. Here is a forum in which neither holds privilege and both are welcome.

But for now, much of the Academy continues to prize and privilege most highly that which is refereed or highly commercially exploitable. Creative writing is unlikely to be either, but it will always be important.

The college in which I teach has a long history of valuing the "applied arts," and here I sit, after hours, applying my art. I am under few illusions. I do not imagine for a moment that any of my students especially care what my “...thoughts on the pursuit of happiness from a midlife vantage point” are, even if I have published an essay under that 
title. Nor would they care that I think there is a lot to be said for "living with lateral purpose," to recall the title of another piece. But what they can and do care about, as I instruct them in avoiding dangling modifiers and faulty pronoun reference, in effectively deploying the passive voice and maintaining a consistent narrative one, is that I have credibility as a writer myself. They care that paid - and paying - editors out there believe my work is worth the paper it is printed on or the e-platform that hosts it. Because if my writing is not worth editorial investment, if it is not worth reading, then what am I doing teaching them?

One of the most appreciative groups of students I teach in Dublin is a PostGraduate class in Public Relations. I teach them Applied English Grammar. Whatever influence can be wielded with the written word, they want. And they want a competent teacher, who writes in the public domain, to help them gain semantic control over style and substance.

My foreign students, by contrast, revel in the self-expression aspects of writing. They are eager to tell their stories as ex-pats, non-nationals, strangers in a strange land. For them, composition serves as a vessel for experience. But they recognize, too, that the clarity of their prose is crucial to their competence as communicators. And so they look to me to guide them through the grammatic and syntactic eccentricities of English. My experience as a writer matters to them, and my own confidence as a teacher derives, once again, from my awareness of the agreeable reception my work has been offered out there, “one step closer," in the real world. The learner-teacher dyad, in this context (i.e. native speaker teaches non-native speaker), requires trust, and I am often sustained in my teaching by the self-knowledge that my own writing has crossed national and cultural boundaries, and so I feel trustworthy. 
I have, in short, no doubt that my writing and teaching inform each other. My identity as an essayist is, to me, barely separable from my identity as a lecturer. I am reminded of a verbal exchange that takes place between Elizabeth Gilbert and a ninthgeneration Balinese medicine man in Gilbert’s best-selling memoir Eat, Pray, Love. While visiting Bali, Gilbert is invited to meet a respected, provincial elder, a prophet, who quickly pegs her as "creative." He says to her, "I think you are good with words. I think this creative work you do is something about words, yes?” To which she replies, "Yes! I'm a writer. I'm a book writer." And in his broken English, with great excitement, he predicts, "someday soon you will come back here to Bali. You must. ... I can practice English with you. I never had anybody to practice English with.” He is so impressed that his new teacher is a real writer that he promises her that in return he will teach her everything he knows. See ya' later, alligator, he says.

I think every Research Support Unit throughout higher education should have on its staff at least one wise Balinese Medicine Man with a sense of humor. Notice, he does not ask Gilbert whether her books are scholarly or not. He swiftly understands that her value as a teacher is greatly enhanced by her reputable engagement with the written word. In his understanding as a learner, her credibility as a practitioner lends her credibility as a teacher.

Maybe I need to live in Bali. Because while $I$ know for sure that my scholarship is greatly enhanced by my creativity, here in Dublin my identity as a "researcher" seems to be defined more by a database than it is by me. If I publish this very essay in a newspaper or magazine, it will not be particularly notable. The repository, a kind of academic totem pole, will have me choose the lesser classification of 
"other.” But if I publish it in a journal or a scholarly book, I can upload it proudly into the refereed top tier.

University research metrics and scholarly repositories need to shift "community engagement" and "creative work" far up the academic totem pole nearer to "peer review" and "international conference presentation." Or else the totem pole should be disassembled. When false dichotomies have fallen away, the homepage of an institution such as my own might read: "Click on the names of our staff members. You will find that they are highly active in their fields of expertise, community engaged, diversely published, and scholars of their disciplines. Step Closer. We are waiting for you, here, in the real world."

\section{Citations:}

EnterText: An Interactive Interdisciplinary Ejournal for Cultural and Historical Studies and Creative Work http://people.brunel.ac.uk/ acsrrrm/entertext/ Brunel University, West London, Ed. Paula Burnett.

Gilbert, Elizabeth. Eat, Pray, Love, New York: Penguin Books, 2006.

Hill, Denise. Editor. NewPages.com, Bay City, MI. http://newpages.com/npguides/litmags_online.htm .

Romano, John. “Coming Home to Television.” Profession 1999. Ed. Phyllis Franklin, 1999, 32-35.

Additional citations will include the author's own publications. 